\title{
MORTE E FINITUDE NA FILOSOFIA DE MARTIN HEIDEGGER: UMA INTUIÇÃO DE SEIN UND ZEIT AO PENSAMENTO DA HISTÓRIA DO SER
}

\author{
José Reinaldo F. Martins Filho ${ }^{1}$ \\ Pontifícia Universidade Católica de Goiás (PUC/GO) \\ (D) https://orcid.org/0000-0001-7722-3729
}

\begin{abstract}
RESUMO:
Pretendemos neste trabalho sustentar a ideia de que, seguindo um percurso que vai de Sein und Zeit aos textos mais tardios, a compreensão do pensar, especialmente tendo em conta a íntima relação desta compreensão com o conceito de existência, esteve caracterizada pela concepção de finitude. Assim, segundo esta hipótese, o pensamento da história do ser (Seinsgeschichtliches Denken) teria como meta revelar ao mesmo tempo o retraimento do ser que se opera por um pensar - chamemo-lo de "expropriador" - e a necessidade de se inaugurar um novo pensar, que é o que estaria em jogo na viragem (Kehre). Intuídos já em Sein und Zeit morte e finitude, firmar-se-iam como conceitos nucleares para a compreensão da importância, do alcance e da posteridade da filosofia heideggeriana.
\end{abstract}

PALAVRAS-CHAVE: Morte; Finitude; Sein und Zeit; Heidegger.

\section{DEATH AND FINITUTE IN MARTIN HEIDEGGER PHILOSOPHY: A INTUITION OF SEIN UND ZEIT TO THOUGHT HISTORY OF BEING}

\begin{abstract}
:
We intend this study support the idea that, following a route that goes from Sein und Zeit to the later texts, understanding the thinking, especially given the close relationship of this understanding to the concept of existence, was characterized by the concept of finitute. Thus, according to this hypothesis, the thought of history of being (Seinsgeschichtliches Denken) would have as

\footnotetext{
${ }^{1}$ Mestre em Filosofia pela Universidade Federal de Goiás (UFG), Goiás - Brasil. Doutorando em Ciências da Religião pela Pontifícia Universidade Católica de Goiás (PUC/GO), Goiás - Brasil. Professor do Instituto de Filosofia e Teologia de Goiás (IFITEG), Goiás - Brasil. E-mail: jreinaldomartins @ gmail.com
} 
its goal revealing at the same time the withdrawal of being that operates by a think - let us call it "expropriating" - and the need to open a new think that is what is at stake at the turn (Kehre). Already intuited in Sein und Zeit death and finitute, would establish itself as key concepts for the understanding of the importance, the reach and posterity of Heidegger's philosophy.

KEYWORDS: Death; Finitute; Sein und Zeit; Heidegger.

Ao longo de Sein und Zeit (SZ) Heidegger insiste em definir o que fundamentalmente tematiza o ente privilegiado, quer dizer, suas estruturas essenciais: a compreensão (Verständigung) e a abertura (Erschlossenheit). ${ }^{2}$ Esta última, contudo, se assentará tanto mais cara à segunda seção desta obra, quanto mais nos aproximamos da pergunta pela relação entre os diferentes modi existenciários do ente Dasein. Lembremo-nos que, antes de tudo, Sein und Zeit pretende se constituir como "uma consideração do ser em geral na sua articulação meta-ontológica com os vários modos de ser possíveis, os quais deveriam ser fenomenologicamente diferenciados e caracterizados" (SA, 2009, p. 4). Desse modo, se, para Heidegger, a demarcação do sentido existencial do Dasein significa o mesmo que a sua definição como poder-ser entendedor, ou, além disso, aquele em cujo ser está em jogo o próprio ser, a noção de existência aqui delineada trará consigo uma conexão ainda mais originária entre a facticidade da experiência geral e cotidiana e a decadência do ente lançado no mundo, marcado por uma compreensão que continuamente se efetua no trato com os demais entes.

Talvez seja esse o motivo que nos conduz ao aparente paradoxo entre o ideal de uma vida autêntica, sempre posto em xeque pela inautenticidade do fenômeno mais imediato e a provável resolução imposta pela descoberta de uma nova instância de possibilidades: "o poder-ser [Seinkönnen] como cada vez meu é livre para a propriedade ou a impropriedade ou a indiferença modal em relação a elas ${ }^{3 \prime \prime}$ (SZ, § 45, p. 233 - grifos do autor). Se, como Heidegger sugere, existência significa poderser, isto é, poder-ser próprio, autenticamente (ainda que não defina precisamente o que entende por "autêntico"), resta-nos compreender de que modo o ente privilegiado alcança a plenitude de sua autenticidade, já que a noção de cuidado (Sorge), ao que tudo indica, não consegue abarcá-la.

\footnotetext{
${ }^{2}$ Cf. Müller-Granzotto (2005, p. 253), “[...] não obstante os diferentes pontos de vista assumidos por Heidegger nas obras compreendidas entre a publicação de Sein und Zeit (1927) e a publicação do artigo La fin de la philosophie et la tache de la pensée (1966), a estrutura da interrogação pelo sentido do ser permaneceu a mesma, [...] o movimento de uma só interrogação."

${ }^{3}$ Cf. $\S 9$, pp. 56 ss (Nota do Autor, doravante N.d.A.).
}

Morte e finitude na filosofia de Martin Heidegger: uma intuição de sein und zeit ao pensamento da história do ser - José Reinaldo F. Martins Filho 
$\mathrm{Na}$ metade do $\S 45$ de Sein und Zeit Heidegger introduz um movimento que para nós parece ser determinante: a cotidianidade à qual nos dirigimos no fenômeno Dasein está circunscrita entre os dois esteios basilares da existência, a vida e a morte. Isso porque a concepção vulgar de existência implica, de antemão, a ideia de finitude como a contingência à que está submetido tudo o que vive e, por extensão, tudo o que é, todo ente, em contraposição à estabilidade ou permanência do ser. ${ }^{4}$

Já a definição inicial do ente Dasein nos põe em contato com este dilema. Para Heidegger, o aí $(d a)$ deve ser entendido como o espaço que ilumina o ser (Sein) - o dar-se, manifestar-se - e, ao mesmo tempo, o que lhe afere a existência como sua maior determinação: "o Dasein se determina cada vez como ente a partir de uma possibilidade que ele é e que, ao mesmo tempo e de alguma maneira, ele entende em seu ser" (SZ, § 9, p. 43). É daí que extraímos o postulado segundo o qual a "essência do Dasein reside em sua existência" (SZ, § 9, p. 42). Conforme atesta Heidegger em Brief über den Humanismus (doravante, $\mathrm{BH}$ ), não podemos admitir qualquer tradução que converta Dasein em um substantivo capaz de indicar a vida fática do homem (cf. BH, p. 38-40). Sobre isso também vale a pena observarmos o seguinte fragmento da carta de Heidegger enviada a Jean Beaufret, em 23 de novembro de 1945: "'Dasein' é uma palavra-chave do meu pensar, por isso ela é causa de graves erros de interpretação. 'Dasein' não significa para mim exatamente eis-me, mas, se é que me posso exprimir num francês sem dúvida impossível: il y a significa exatamente alétheia, desvelamentoabertura" (cf. BH, p. 89). ${ }^{5}$ Dasein é manifestação primordial. É o aí que se orienta para o ser e, por isso, o destaque em alemão, adequado ao sentido deste termo, seria Dasein, ao invés de Dasein (cf. ZoS, p. 156). Deve ser lido verbalmente, como o ente que está se fazendo presente, como o substrato da frase "ich bin da", ou seja, "eu estou aqui", "estou presente", e isto é a facticidade da existência. Conforme o entendimento de Sein und Zeit, o da indica a abertura do Dasein, como o horizonte transcendental de compreensão dos entes - $d a$ enquanto Erschlossenheit do mundo. Nesse sentido, conforme Peter Sloterdijk (2000, p. 24), "Heidegger oferece-se para pôr fim à imensurável omissão do pensamento europeu - a saber, não ter levantado a questão sobre a essência do ser humano da única maneira apropriada, que, para ele, é a maneira existencial-ontológica."

$\mathrm{Na}$ preleção Was ist metaphysik? (WM), de 1929, Heidegger novamente justifica o uso de Dasein em sua filosofia. Segundo ele, "para reunir, ao mesmo tempo, [...] tanto a relação do ser com a essência do

\footnotetext{
${ }^{4}$ Ver Pisetta, Morte e finitude, 2007, p. 220ss (vide bibliografia).

${ }^{5}$ Também em outras obras encontramos o esforço de Heidegger por traduzir o sentido da expressão Dasein, como, por exemplo, na seguinte passagem de Zollikoner Seminare: "Em Sein und Zeit, o da não significa uma indicação de localização para um ente, mas deve nomear a abertura na qual o ente pode ser/estar presente para o homem, também ele mesmo, para si mesmo. O aí (da) para o ser distingue o ser-homem" (ZoS, p. 156ss).
}

Morte e finitude na filosofia de Martin Heidegger: uma intuição de sein und zeit ao pensamento da história do ser - José Reinaldo F. Martins Filho 
homem, como também a referência fundamental do homem à abertura (aí) do ser enquanto tal, fora escolhido, para o âmbito essencial em que se situa o homem enquanto homem, o nome Dasein" (WM, p. 58). Não é, portanto, por caprichos terminológicos que substantivos como "vida", "homem" ou "sujeito" são evitados em Sein und Zeit. Comentando a crítica de Karl Jaspers a Heidegger, sobretudo no que tange à relação ser e ente, Mondadori salienta a impossibilidade de se "separar este conteúdo do jogo que confunde sempre Dasein e existência, ser e liberdade, que quer dizer uma coisa pela outra, e trata o objeto do saber como evidência que há de ser analisada pelo estado de ânimo, como realização da existência, como acontecimento" (MONDADORI, 1990, p. 9 - grifo nosso). E isso ainda pode ser ilustrado pelo que Heidegger salienta em Brief über den Humanismus $(\mathrm{BH})$, ao caracterizar a "propriedade" do ser sobre o ente e, simultaneamente, a sua transparência no fenômeno Dasein: "aquele que joga no projetar não é o homem, mas o próprio ser que destina o homem para a existência do Dasein como sua essência" (BH, p. 161). Portanto, se o Dasein é um ente, é um ente que põe em jogo seu próprio ser. Em Was ist Metaphysik?, lemos: "a frase: 'o homem existe' significa: o homem é aquele ente cujo ser é assinalado pela insistência existente no desvelamento do ser a partir do ser e no ser" (QM, p. 59). Velar-se para as coisas significa compenetrar-se na compreensão de si. Para este ente, existir sempre será existir em função da compreensão do ser, isto é, insistir em ser, ou ainda, "ter que ser" (cf. SZ, § 9).

Consequentemente, voltando-nos para a definição do ser do homem como existência insistente o maior peso será atribuído ao fenômeno da morte, e não mais à noção de cuidado (Sorge), como podemos notar:

\begin{abstract}
Não há dúvida de que se afirmou que o cuidado [Sorge] é a totalidade do todo-estrutural da constituição-do-Dasein ${ }^{6}$ [Daseinsverfassung]. Mas a rejeição da possibilidade de pôr sob o olhar o Dasein como um todo já não reside no ponto-departida da interpretação? De fato, a cotidianidade é, no entanto, precisamente o ser "entre" o nascimento e a morte. E, se a existência determina o ser do Dasein e sua essência é coconstituída ${ }^{7}$ pelo poder-ser, então o Dasein, podendo ser enquanto existir, deve ser cada vez algo de ainda não sendo [noch nicht sein]. [...] Enquanto ele é, há cada vez no Dasein algo que falta, que ele pode ser e que ele será. Mas a esse faltante pertence o "final" ele mesmo. O "final" do ser-nomundo é a morte (SZ, § 45, p. 234 - grifos do autor).
\end{abstract}

Se desde o seu $§ 9$ Sein und Zeit insiste na ideia de um ente dotado de certa precedência, para quem a essência consiste em ter-que-ser na

\footnotetext{
${ }^{6}$ Cf. $§ 41$, pp. 254 ss (N.d.A.).

${ }^{7}$ Ao mesmo tempo: o já-ser (N.d.A.).
}

Morte e finitude na filosofia de Martin Heidegger: uma intuição de sein und zeit ao pensamento da história do ser - José Reinaldo F. Martins Filho 
abertura para as possibilidades da existência, do $§ 45$ em diante a concepção de horizonte de possibilidades estará dotada de uma força ainda maior: Dasein é o ente marcado pelo constante jogo entre aquilo que já é e o que ainda não é. De nossa parte, também não podemos deixar de observar o peso outra vez depositado sobre a noção de existência, ela mesma, como condição de possibilidade para a compreensão do ente humano. Há um nexo irrenunciável entre as ideias de existência, entendida como abertura para o possível, e de horizonte ${ }^{8}$ - o que implica considerarmos em que medida o trato com a finitude já não estaria aqui contemplado. Heidegger não pretende tratar a morte como o simples fenômeno da contingência dos corpos, mas, de outro modo, como a alternativa para uma interpretação existenciária genuína. Não será a morte, porquanto, o objeto da análise, mas o ser-para-a-morte (Sein-zum-Tode), que se efetua como um modus de ser do ente privilegiado, impelindo-o à completude de seu sentido de ser (Seinssine) em geral. Nosso problema, portanto, situa-se deste ponto em diante.

Ora, de que maneira a morte, vislumbrada no existenciário ser-paraa-morte, torna possível ao Dasein o acesso à compreensão de si mesmo e da existência como finitude e, por esse intermédio, à promessa de uma vida autêntica? Responder a esta pergunta certamente nos permitirá traçar os pontos que servirão de norte para uma interpretação filosófica da própria finitude humana - nesse caso, amplamente considerada pela filosofia de Martin Heidegger, desde a gênese até os ulteriores desdobramentos da Kehre. Mais que isso, nos permitirá aquilatar o lugar da morte na esteira de um pensamento que continuamente se desenvolve ao redor do tema da finitude. Ser-para-a-morte e finitude não remetem apenas às experiências extremas da existência, mas podem nos auxiliar na formulação de uma nova perspectiva para a compreensão do homem em sua relação com o ser - de sorte que o tema da finitude poderá ser ulteriormente identificado, em todo o pensamento da história do ser (Seinsgeschichtliches Denken).

Heidegger inicia o primeiro capítulo da II seção de Sein und Zeit chamando a atenção para a necessidade de vencer o que há de insuficiente na situação hermenêutica da qual surgiram suas anteriores análises do Dasein. Desse modo, provavelmente se referia ao fato de a questão do serpara-a-morte ter surgido unida ao problema, ainda em aberto, da eventual apreensão de um ser-todo (Ganzsein) deste ente. Ao que parece, a análise do cuidado (Sorge) não conseguiu restituir a compreensão do ser todo, porque manteve o Dasein no nível da inautenticidade do trabalho com os outros. No cuidado o Dasein acaba por perder-se nos outros: "ele não é si-mesmo, os

\footnotetext{
${ }^{8}$ Isso já estava de algum modo contemplado em Husserl nos conceitos de horizonte de possibilidades e de protensão da intenção: "tratar-se-á de uma cadeia de recordações intuitivas, com a infinidade ilimitada do horizonte potencial do "posso sempre reproduzi-lo de novo"” (MC, §27, p. 81; cf. Hua I, p. 96).
}

Morte e finitude na filosofia de Martin Heidegger: uma intuição de sein und zeit ao pensamento da história do ser - José Reinaldo F. Martins Filho 
outros lhe retiram o ser" (SZ, § 27, p. 126). Além disso, quando aborda a impossibilidade de uma assimilação totalizante do Dasein pelo cuidado, Heidegger se dirige ao dado já mencionado de que ser para as possibilidades requer constante incompletude. Talvez por isso possamos adiantar que o significado heideggeriano de ser-para-a-morte, extraído dos $\S \S 45$ e 46 de Sein und Zeit, enquanto se distancia de qualquer construção vulgar de uma ocorrência de morte, equivale ao que poderíamos nomear pela ideia de um ser-para-a-falta. Nalguma medida, a noção de cuidado acaba por anular esse ser faltante quando estabelece as ocupações do Dasein. A eliminação da falta depõe a favor do aniquilamento do ser próprio do Dasein. Será justamente esse "ainda não ser", ou melhor, esse "ser da falta", o que estará identificado, num sentido genuinamente existencial, ao fenômeno da morte. Daí que, conforme Pisetta (2007, p. 229), "se a morte pode ser concebida como uma interrupção, que num momento pode ocorrer, sua apreensão e compreensão acontecem a todo momento somente de modo prévio". Quer dizer que também este ser-todo (Ganzsein) apenas será possível antecipadamente, experimentado, tão logo, pelo viés da possibilidade.

Em primeiro lugar, é preciso delimitar que o conceito prévio de morte parte do fenômeno cotidiano do ser-com-os-outros (Miteinandersein), derivado, por sua vez, do modus existenciário ser-com (Mitsein). Numa experiência de morte os sobreviventes permanecem junto ao corpo do finado como expectadores, numa mera atitude de "preocupação-com-ooutro" (ehrenden Fürsorge), ainda que jamais reduzida à ocupação (Besorge) junto a um utilizável (Zuhandenen). Com isso Heidegger quer dizer que não possuímos um conhecimento direto da morte, a não ser por intermédio da morte dos outros. Esta, à sua maneira, não nos dá a visão própria do morrer, mas, antes, a da falta. Daí que a percepção afetiva que simultaneamente nos interpela e instiga à consideração da morte seja, num primeiro contato, uma sensação de ausência. Em resumo, diz Heidegger:

O que se discutiu até agora sobre a morte pode ser formulado em três teses: 1. Ao Dasein, enquanto ele é, pertence um aindanão que ele será - o faltante constante. 2 . O chegar-ao-seu-final [Zu-seinem-ende-kommen] do cada vez ainda-não-sendo-nofinal [Noch-nicht-zu-Ende-seienden] - a eliminação, conformeao-ser, do faltante - tem o caráter do já-não-Dasein [Nichtmehrdaseins]. 3. Para o Dasein de cada vez, o chegar-aofinal contém em si um modo-de-ser pura e simplesmente insubstituível (SZ, § 48, p. 242).

Considerados estes passos, perguntamo-nos de que forma tudo isso aparecerá articulado no modus ser-para-a-morte (Sein-zum-Tode). Em resposta, segundo Heidegger é preciso distinguir entre o que significa serpara-a-falta do simplesmente faltante, ou seja, daquilo que está ausente. Este último somente se aplica para os entes instrumentais do interior do

Morte e finitude na filosofia de Martin Heidegger: uma intuição de sein und zeit ao pensamento da história do ser - José Reinaldo F. Martins Filho 
mundo circundante. Dasein, ao contrário, é para a falta com a mesma intensidade em que está presente para si, sempre e unicamente, na condição de ser-no-mundo. Faltar, nesse caso, é da ordem de uma teleologia, de um direcionamento rumo ao fim. Como salienta Pisetta (cf. 2007, p. 231), o serpara-a-morte é um relacionamento libertador e liberador. Liberador porque libera das prisões do impessoal e libertador porque, em libertando da ditadura do impessoal, lança o Dasein para a singular experiência de si mesmo e para uma genuína liberdade como compromisso com o próprio, o irremissível e insuperável, o certo mas indeterminado, em cada possibilidade de fato. Ainda segundo esse intérprete, "o fim carrega um sentido teleológico, mas que não deve ser compreendido pragmaticamente. Assim, o fim mortal por nós visado, não está a serviço da volição" (PISETTA, 2007, p. 226-227). O mesmo é reforçado pela seguinte citação: "o Dasein não começa a ser quando seu ainda-não é preenchido, momento em que ele, ao contrário, precisamente já não é. O Dasein existe sempre e cada vez já de tal maneira que seu ainda-não lhe pertence" [diríamos: como uma possibilidade] (SZ, § 48, p. 243 - grifos do autor).

Dasein é ser-para-a-morte apenas enquanto vive e se projeta ao horizonte dos possíveis. Daí que em Heidegger a certeza de si signifique certeza de si como mortal, e Sum queira sempre dizer Sum moribundus (cf. DUBOIS, 2004, p. 50). Diz o autor: "o Dasein, do mesmo modo que enquanto $e$, já $e ́$ constantemente o seu ainda-não, já é sempre também o seu final. O findar que é pensado com a morte não significa um ter-chegado-aofinal do Dasein, mas ${ }^{9}$ um ser-para-o-final desse ente. A morte é um modo de ser que o Dasein assume logo que é" (SZ, § 48, p. 245 - grifos do autor). Curiosamente, o arremate conclusivo para essa ideia é impresso por Heidegger através da menção de um antigo ditado alemão: "sobal dein Mensch zum Leben kommt, sogleich ist eralt genug zu sterben" [um humano, logo que nasce, já é bastante velho para morrer - tradução de Fausto Castilho]. ${ }^{10}$ Recordando, portanto, a analogia de Dubois (2004), tudo o que foi dito acima poderia ser resumido na expressão: o Dasein jamais perece, e só pode falecer porque morre.

Verdade seja dita, não podemos atribuir unicamente a Heidegger o trato com o tema da morte e sua relação com a dinâmica da vida. A segunda nota de rodapé, aposta pelo autor em seu exemplar de uso na metade do $\S 49$ de Sein und Zeit recorda que "a antropologia elaborada na teologia cristã -

\footnotetext{
${ }^{9}$ A morte como morrer (N.d.A.).

${ }^{10}$ Em português também encontramos alguns ditados semelhantes: "basta nascer e já se está pronto para morrer" ou, ainda, "para morrer, basta ter nascido". Na página 245 de Sein und Zeit, em que inscreve o ditado popular alemão, Heidegger também menciona a sua fonte: "Der Ackerman naus Böhmen [O camponês da Boêmia], editado por A. Bernt e K. Burdach (Vom Mittelalter zur Reformation, Forschungen zur Geschichte der deutschen Bildung [Da Idade Média à Reforma. Pesquisas da história da Educação Alemã], editado por K. Burdach, vol. III, $2^{\text {a }}$ Parte), 1917, cap. 20, p. 46" (N.d.A.).
}

Morte e finitude na filosofia de Martin Heidegger: uma intuição de sein und zeit ao pensamento da história do ser - José Reinaldo F. Martins Filho 
desde Paulo de Tarso até a meditatio futurae vitae de Calvino - sempre viu a morte incluída na interpretação da vida" (SZ, § 49, p. 249 - nota 2). Além disso, o filósofo ainda destaca o papel de teóricos contemporâneos, os quais também se colocaram frente ao tema da morte. Seria o caso de Wilhelm Dilthey, Georg Simmel ou Karl Jaspers. Todos os três relacionaram morte e vida, sendo a primeira apontada como o fenômeno da situação limite. O mesmo ocorreu no $\S 40$ de Sein und Zeit, firmado como primeiro ponto de intersecção entre a abertura da angustia e o ser-para-a-morte. Ora, se, conforme Heidegger, "a absorção em a-gente [das Man] junto ao mundo da ocupação manifesta algo assim como uma fuga do Dasein diante de si mesmo como poder-ser-si-mesmo próprio" (SZ, § 40, p. 185), a angústia, do contrário, traz à tona "o ser para o poder-ser mais próprio, isto é, o ser livre para a liberdade do-a-si-mesmo se-escolher e se-possuir" (SZ, § 40, p. 188 - grifos do autor). Assim, a angústia põe o Dasein como propensio in, aberto para ser livre e, nesse caso, disponível ao apelo da morte. Se, em termos religiosos, a morte é compreendida como a libertação deste vale de angústias e sofrimentos, a perspectiva que empreendemos apontará para um caminho absolutamente inverso. O ser-para-a-morte efetuará uma liberação que se dirige a outro nível, como segue: ao âmbito das possibilidades existenciais.

Quando pensamos nos principais modos de dispor-se do ente Dasein, especialmente o temor e a angústia, constatamos que a temática do ser-para-a-morte já é de algum modo introduzida desde o $§ 40$ de Sein und Zeit. Mas como entendermos o sentido ontológico da morte como "possibilidade nas impossibilidades" (SZ, § 53)? Segundo Heidegger, "a morte se desvenda como a possibilidade mais-própria, irremetente $e$ insuperável" (SZ, § 50, p. 251 - grifos do autor) à qual o Dasein se sujeita. $E$ isso não ocorre tendo em vista o fenômeno contingente do morrer. Nesse caso, a morte é especificamente apreendida como uma possibilidade-de-ser que o ente mundano deve assumir sempre e unicamente por si só. "Puramente, ela é o que vem; não reside senão nessa vinda. Mas nessa vinda, como vinda de nada no mundo, é precisamente o ser-no-mundo enquanto tal que se abre, avaliado em sua nudez" (DUBOIS, 2004, p. 50 grifo meu).

Heidegger já havia mencionado algo de semelhante quando tratava dos modos privilegiados de encontrar-se (Befindlichkeit) do ente que sempre somos. Naquela oportunidade disse o autor: "a dejecção na morte se lhe desvenda do modo mais originário e mais penetrante no encontrar-se da angústia $^{11}$. A angústia diante da morte é a angústia 'diante' do mais-próprio, irremetente e insuperável poder ser” (SZ, § 50, p. 252). Angústia aqui não sugere apenas um estado de ânimo ou uma disposição de humor. Ao contrário, à semelhança de todas as vezes em que esse conceito esteve em

\footnotetext{
${ }^{11}$ Cf. $\S 40$, pp. 244 ss. (N.d.A.).
} 
cena, angustiar-se significa abertura (Erschlossenheit) e reconhecimento, o reconhecimento de que para este ente existir é sempre ser-para-o-fim, quer dizer, para a morte; um empreendimento da finitude. O mesmo encontramos no comentário de Hervé Pasqua (1993, p. 127), para quem "a angústia não é a fuga diante da morte, mas o enfrentar da possibilidade da nossa própria impossibilidade", e aqui está um dos maiores segredos da existência. Por isso, o que nos convém reter como principal resultado do $\S 50$ de Sein und Zeit talvez seja o fato de que no ser-para-a-morte o Dasein relaciona-se com seu poder-ser mais insigne. A morte, como objeto de sustentação de um discurso ontológico, torna-se o auge daquela empresa que, por se referir à identidade do ente decaído no mundo, denominamos existência. Diz Heidegger: "existência, factualidade, decair caracterizam o ser para o final e são, por conseguinte, constitutivos para o conceito existenciário de morte. $O$ morrer se funda no cuidado [Sorge] quanto a sua possibilidade ontológica $^{12,}$ (SZ, § 50, p. 252 - grifos do autor).

De forma sucinta, todo o discurso heideggeriano de Sein und Zeit sobre o ser-para-a-morte se encontra resumido no seu $\S 53$. Nele, após ter tentado superar os impedimentos que, porventura, obscureciam a compreensão deste modus existenciário, Heidegger determina que, antes do mais, é preciso que se caracterize a morte como um "ser para uma possibilidade, isto é, para uma possibilidade assinalada do Dasein ele mesmo" (SZ, § 53, p. 261). No âmbito da experiência concreta do dia a dia, na impropriedade do ser-uns-com-os-outros, isso poderia ser exemplificado pela forma do atingível, do dominável, do viável, em resumo, no constante empenho em prol da anulação de uma possibilidade real. Nada obstante, devemos concordar que a morte não está dada no nível daquilo que é passível de efetiva conclusão. Dito de uma maneira mais simples, o ente Dasein não pode simplesmente se ocupar da morte, como faz com os demais instrumentos pré-dispostos à lida. Disso decorre que quando Heidegger se refere ao ser-para-a-morte enquanto possibilidade tem em vista o seu ininterrupto direcionamento ao universo dos possíveis: sua abertura de pronto, representada por uma seta constantemente dirigida para fora, para o novo e, nesse caso, para o intangenciável. Dessa forma, existir significa, imprescindivelmente, estar aberto à possibilidade, do que procede que serpara-a-morte apenas se legitima como condição para o ente existente, e apenas na medida em que existe: "no ser-para-a-morte [...] a possibilidade deve ser entendida como possibilidade sem atenuação, tem de ser desenvolvida como possibilidade e no comportamento relativo a ela tem de ser sustentada como possibilidade (SZ, § 53, p. 262 - grifos do autor).

Talvez esse seja um dos mais ricos aspectos do ser-para-a-morte heideggeriano que, ao mesmo tempo em que se dirige para a morte como resolução antecipadora, resgata o sentido magistral da vida como abertura

${ }^{12}$ Mas o cuidado [Sorge] se desdobra a partir da verdade do ser (N.d.A.).

Morte e finitude na filosofia de Martin Heidegger: uma intuição de sein und zeit ao pensamento da história do ser - José Reinaldo F. Martins Filho 
ilimitada rumo ao horizonte dos possíveis - e isso, sobretudo, nos interessa. Ser-para-a-morte de algum modo quer dizer ser-para-a-vida, pois a morte apenas pode ser encarada como a libertação do abismo arrebatador da inautenticidade, sendo que a "máxima proximidade do ser-para-a-morte, como possibilidade, está o mais longe possível do efetivamente real" (SZ, § 53 , p. 262). Sua certeza se dá pelo fato de que a cada instante continua sendo horizonte. Sempre é possível morrer, uma vez que se vive. Não se trata de uma noção imediata da morte, mas de compreendê-la como abertura constante. Antecipando-se na morte o Dasein alcança a garantia de ser ele próprio: "o ser-para-a-morte como adiantar-se na possibilidade possibilita essa possibilidade e, como tal, põe-na em liberdade" (SZ, § 53, p. 262 grifo do autor). Isso é a "liberdade para a morte", fruto da angústia pelo morrer (cf. DUBOIS, 2004, p. 51). É liberdade apaixonada, factual, certa de si mesma e desembaraçada das ilusões impessoais (cf. SZ, § 53). Tal liberdade assume um papel muito além do simples libertar-se. Não se trata de uma liberdade no sentido convencional, mas, como salienta Pasqua (1993, p. 131), da "vertigem que acompanha a queda do ser no nada. É um mergulhar no fim, no qual todo ser, esvaziado de si próprio, se identifica com o nada".

O caráter positivo do Ser-para-a-morte, consequentemente, torna-se o nexo necessário para que o Dasein extraia uma autêntica compreensão de si e, por acréscimo, do ser: "projetar-se sobre o poder-ser mais próprio significa poder se entender a si mesmo, no ser do ente assim desvendado: existir" (SZ, § 53, p. 263). Mas isso não é tudo. Ser-para-a-morte também é sinônimo de abertura para a compreensão de si como existência finita, de modo que o contato inicial da filosofia heideggeriana com a finitude, promovido já em Sein und Zeit, põe-se como resposta à questão identitária do ente que se resolve na relação com a morte:

O adiantar-se abre para a existência, como possibilidade extrema, o dom-de-si, e rompe assim toda rigidez da existência já alcançada em cada caso. Ao adiantar-se, o Dasein se resguarda de vir a se atrasar em relação a si e ao seu poder-ser já entendido e de se tornar "demasiado velho para suas vitórias" (Nietzsche). Livre para as possibilidades maispróprias e determinadas a partir do final, isto é, entendidas como finitas, o Dasein afasta o perigo de não reconhecer, a partir do seu entendimento finito da existência, as possibilidades de existência dos outros que o superam ou então, por interpretá-las mal, reduzindo-as às suas possibilidades, e assim ele mesmo renuncia à sua existência factual mais-própria (SZ, § 53, p. 264 - grifos do autor).

Tomando como base este fragmento e aderindo à interpretação de Pisetta (2007), assumimos que, em um primeiro momento, a finitude deve ser encarada como a compreensão que se revela desde o fim, nesse caso, desde a morte. No final de todas as realidades objetivas desvelar-se-á a

Morte e finitude na filosofia de Martin Heidegger: uma intuição de sein und zeit ao pensamento da história do ser - José Reinaldo F. Martins Filho 
clareza que o Dasein efetua acerca dos outros ou das coisas, sempre e unicamente pelo viés da possibilidade. Dessa forma, o Dasein "compreendese como sendo não uma substância ou essência 'fora' do tempo que passa, que morre, 'que devora seus filhos', mas como um poder-ser, como aberto e livre para possibilidades finitas, porque é, em si mesmo, esse modo de ser finito, isto é, circunstancial, segundo limites" (PISETTA, 2007, p.233). Assim, podemos dizer que no vínculo entre a noção de ser-para-a-morte e o conceito de finitude da existência, que agora se delineia mais claramente, Heidegger circunscreve a sua proposta de apresentar o sentido do ser deste ente, entendendo por tal ser não uma forma objetiva ou uma abstração do plano ôntico, mas uma ocupação, um operar, um cuidado - que em sua forma autêntica é capaz de se compreender como um movimento de transcendência, que é sua própria temporalidade, e nesse sentido, sua finitude (cf. MÜLLER-GRANZOTTO, 2005, p. 257). Mas como se estabelece a relação entre morte e finitude, amadurecida na ampla seara do pensamento heideggeriano? E como entender o sentido positivo assumido por estes conceitos, retirando-os da aparente obscuridade na qual parecem estar imersos?

Em um de seus ensaios de 1929, intitulado Vom Wesen des Grundes (VWG), Heidegger recupera algo que já havia sido objeto das análises de Sein und Zeit, como segue: a noção de finitude como essência do Dasein. Diz o autor: "a explicitação da essência da finitude do Dasein a partir de sua constituição ontológica deve preceder a toda base óbvia da natureza finita do homem, a toda descrição de qualidades que somente são consequências da finitude, e, por último, a todos os esclarecimentos sobre a origem ôntica da mesma" (VWG, p. 115). Em poucas palavras, esta passagem consegue sintetizar o que a volumosa obra heideggeriana tentou, a cada vez, afirmar. Como ocorreu na tematização da morte, também em se tratando da finitude Heidegger não pretende partir de uma compreensão vulgar do termo, aquela que se dirige ao término da matéria ou àquilo que possui um fim material o que os filósofos do passado estabeleceram sob o título de contingência. A novidade que Heidegger imprime ao conceito de finitude não está atrelada a qualquer papel que este já tenha ocupado na história da filosofia: "o antigo significado de nossa palavra 'fim' [Ende] é o mesmo que o da palavra 'lugar' [Ort]: 'de um fim a outro' quer dizer: 'de um lugar a outro'. [...] Fim é, como acabamento, a concentração nas possibilidades supremas” (FdF, p. 72).

Tanto no Discours de la Méthode, quanto em Meditationes de prima philosophia, Descartes já havia convocado a noção de finitude para o âmbito das reflexões filosóficas. ${ }^{13}$ Naquela altura apenas considerou o tema

\footnotetext{
${ }^{13}$ Estamos diante de uma das ambivalências do termo finitude em Heidegger, que tanto quer dizer acerca de um direcionamento rumo ao fim, quanto nomear o finito, ou seja, o que possui limite. O fato é que, em ambos os casos, trata-se de uma aplicação cuja originalidade mantém distância dos demais empregos aos quais a filosofia recorrera ao longo da história.
}

Morte e finitude na filosofia de Martin Heidegger: uma intuição de sein und zeit ao pensamento da história do ser - José Reinaldo F. Martins Filho 
da finitude como definição do status humano em oposição ao ens infinitum creator omnium. ${ }^{14}$ Isso, notadamente, nada mais pode representar senão o que fora convencionado pela metafísica tradicional, quer dizer, o entendimento de finitude como uma característica dos entes que se modificam ou têm limites. Mas em que consiste a novidade heideggeriana? $\mathrm{O}$ que, stricto sensu, Heidegger pretende pela noção de finitude? $\mathrm{O}$ que significa a descrição do homem no plano ontológico como dotado não apenas de uma natureza finita?

Segundo Schurch (cf. 2010, p. 9), o que o pensamento de Heidegger desenvolve e constrói sobre a compreensão de finitude não é apenas diferente dos exemplos históricos da filosofia que acabamos de mencionar, mas incompatível com estes, que não entenderam suficientemente o seu conteúdo filosófico. Conforme o mesmo autor, desde o nascimento do cristianismo a finitude tem sido entendida em oposição a uma ideia própria de infinito equivalente à perfeição, quer dizer, o finito é o pobre, o limitado, o imperfeito, necessariamente, o deficiente em comparação com a perfeição infinita. Disso decorre que a noção de finitude impressa pela filosofia heideggeriana como a marca característica do ente humano não poderia se inscrever num mesmo nível do debate entre a inversão dos conceitos finito e infinito $^{15}$. No final do $\S 65$ de Sein und Zeit, Heidegger insiste na finitude da temporalidade originária e, naquele contexto, diz que esta não é a

$\mathrm{Na}$ terceira de suas meditações, Descartes recorre à noção de finitude com o intuito de justificar a existência de Deus, tal como, no Discours de la Méthode, procedera por meio dos conceitos de perfeição versus imperfeição. Pensar o infinito e o perfeito, no contexto cartesiano, implica legitimar a existência de um outro ser, anterior a este que se descobre no âmbito da finitude e da imperfeição. Ora, a prova da existência de Deus acaba por auxiliar na caracterização do ente humano, aquele que se opõe à infinitude divina. Diz Descartes (2000b, p. 281): "mesmo que a ideia de substância esteja em mim, pelo próprio fato de ser eu uma substância, não teria a ideia de uma substância infinita, eu que sou um ser finito, se ela não tivesse sido colocada em mim por alguma substância que fosse de fato infinita". Um pouco adiante continuaria o mesmo autor: "e não devo imaginar que não concebo o infinito mediante uma ideia verdadeira, mas apenas pela negação do que é finito [...],pois é da natureza do infinito que minha natureza, que é finita, não possa compreendê-lo" (DESCAR-TES, 2000b, pp. 281-283 - grifos nossos). Cf. também Schurch, 2010, p. 8.

${ }^{14}$ Sobre isso, ver Schurch (2010), Heidegger et la Finitude, especialmente no que se refere à sua abordagem introdutória, que visa recapitular os diferentes sentidos atribuídos ao termo finitude ao longo da história do pensamento ocidental.

${ }^{15}$ Cf. Fraga (1966, p. 88), mesmo entre Husserl e Heidegger há uma importante diferenciação no que respeita ao conceito de finitude: "a conclusão do pensamento de Sein und Zeit, que se mantém na obra posterior de Heidegger, insiste na finitude do ser-aí que impede toda a aproximação de um panteísmo transcendental, mas a relação à história, porque determinada pelo próprio ser, tem uma dimensão extra-humana, dimensão indeterminada como o próprio ser, cujo sentido se dá, possivelmente, no âmbito insuficiente da linguagem. A conclusão paralela do pensamento de Husserl é, repetindo Fink, semelhante à dos grandes idealistas; a relação do homem ao infinito consiste em um ser infinito do sujeito, que, por outro lado, se finitiza."

Morte e finitude na filosofia de Martin Heidegger: uma intuição de sein und zeit ao pensamento da história do ser - José Reinaldo F. Martins Filho 
temporalidade baseada no infinito, que, aliás, acabava de ser desconstruída. A finitude da temporalidade autêntica é introduzida a partir da definição do ser-para-a-morte: "em tal ser para o seu final, o Dasein existe propriamente todo como o ente que pode ser 'dejectado na morte' [geworfen in den Tod]. Ele não tem um final em que simplesmente termine, mas ele existe de modo finito [existiert endlich]" (cf. SZ, § 65, p. 330 - grifos do autor). Tal significação antecede aquela que talvez seja uma das passagens mais difíceis de Sein und Zeit: "sua finitude não significa primariamente um terminar, mas é um caráter de temporalização ela mesma" (cf. SZ, § 65, p. 330). Mas, por que a finitude, por ela mesma, implica temporalização? Haveria alguma relação entre a noção de temporalidade implicada pela finitude e a morte como resolução antecipadora? Ao que parece, Heidegger pretende indicar que a noção de temporalidade somente encontra legitimação enquanto vinculada à existência do ente mundano, mesmo que não confundida com ele ${ }^{16}$ : “com a tese da finitude originária da temporalidade não se nega que o 'tempo prossegue', mas que esta tese só pretende manter com firmeza o caráter fenomênico originário do Dasein ele mesmo" (cf. SZ, $\S 65$, p. 331). Nada obstante, até que ponto isso é desenvolvido pela filosofia heideggeriana, sobretudo pelos escritos posteriores a Sein und Zeit, quando o trato com a finitude parece ganhar outros contornos, ampliando-se rumo à constituição de uma Seinsgeschichte?

De algum modo, a imagem de finitude cunhada por Sein und Zeit está relacionada a uma ideia de negação. Não como rebaixamento, à semelhança do que fizeram os medievais, mas no que Heidegger entende como o sentido positivo da negação, articulado ao redor de dois conceitos essenciais: a morte e o nada. Ainda não sabemos ao certo como se efetua a relação entre finitude e o nada, contudo, se o conceito existenciário do serpara-a-morte abre ao Dasein um horizonte de possíveis capaz de remetê-lo ao seu ser mais próprio, o mesmo certamente deverá ocorrer para uma compreensão de finitude que não se submeta aos mesmos parâmetros da dicotomia erigida entre finito e infinito: "Heidegger não discute antropologicamente a finitude ou infinitude do homem. Interessa-o a finitude e a temporalidade que nele representam abertura para o ser" (STEIN, 2001, p. 292). Nesse sentido, qual o papel atribuído à análise ontológica do nada e sua articulação com os conceitos morte e finitude no pensamento heideggeriano? Esta questão apenas se soma às demais suscitadas ao longo desta exposição e, como as outras, sua resposta exige de nós a decisão de percorrer o longo itinerário que compõe a filosofia de Martin Heidegger.

\footnotetext{
${ }^{16}$ Cf. Ferreira (2003, p. 11), "a temporalidade não se identifica com o homem ou com as coisas, antes possibilita a manifestação de homem e mundo; neste sentido, o tempo pode ser dito tanto o fundamento de possibilidade da compreensão do ser quanto o princípio de individuação e singularização do ser."
}

Morte e finitude na filosofia de Martin Heidegger: uma intuição de sein und zeit ao pensamento da história do ser - José Reinaldo F. Martins Filho 
Como chegamos a afirmar, já em Sein und Zeit a questão da finitude não é, de modo algum, um elemento periférico. No entanto, são os escritos posteriores à década de 1930 que acabaram tornando-a um dos temas diretores da filosofia heideggeriana. Trata-se do traço que propriamente iluminaria a abordagem do Dasein e, quiçá, permitiria a constituição de um pensamento sobre a história do ser (Seinsgeschichtliches Denken). Nos Beiträge zur Philosophie $(\mathrm{BPh})$, por exemplo, alguns parágrafos retornam à análise do ser-para-a-morte como abertura à compreensão do ser: "a singularidade da morte no Dasein pertence à mais originária determinação, a saber, ser apropriado pelo ser. Na inabitualidade e singularidade da morte se inaugura o mais habitual em todo ente, o ser mesmo" (BPh, p. 230). Isso significa que à semelhança de Sein und Zeit, também nos escritos posteriores à Kehre a noção de morte sempre apareceria articulada à finitude - não aplicada, contudo, nem à negatividade do ente humano em oposição a qualquer ideal de infinitude divina, nem, sequer, como a simples ocorrência contingente de um ente dotado de fragilidades ${ }^{17}$. Nada obstante, se em Sein und Zeit pelo termo finitude Heidegger almejava apresentar o modo identitário do Dasein, quer dizer, o modus de ser que, entre os demais, melhor poderia defini-lo, com o passar dos anos a filosofia heideggeriana acabou elaborando uma noção de finitude também aplicada ao ser - mais propriamente, ao pensamento da história do ser (Seinsgeschichtliches Denken). Ora, o ser é finito porque apenas se dá enquanto há Dasein. Assim, a compreensão da finitude do Dasein torna-se determinante sobre a própria compreensão da finitude do ser, sendo que, segundo Heidegger, ao longo da própria história da filosofia torna-se possível identificar elementos capazes de corroborar este argumento.

Tomando por base o que fora dito, notamos que a filosofia heideggeriana é responsável por um claro alargamento na concepção de finitude, inicialmente proposta por Sein und Zeit e posteriormente desenvolvida em Kant und das problem der metaphysik (1929) e Beiträge zur Philosophie (1936-1938) - o que, provavelmente, não poderíamos notar no horizonte específico da obra de 1927. Como dissemos, para o último Heidegger a própria compreensão de ser deverá ser tomada na perspectiva da finitude, tal como em Sein und Zeit ocorrera com a definição do ente por excelência. Nesse sentido, estamos plenamente de acordo com a definição proposta por Ernildo Stein (2001, p. 389), para quem "Heidegger é o filósofo da finitude". Antes de tudo, porque não há outro caminho para o discurso ontológico senão aquele mediado pelo ente finito, o homem da existência cotidiana. Além disso, porque o próprio ser também se torna finito, na medida em que se manifesta unicamente a partir da finitude do Dasein. Disso decorre que tanto a filosofia, quanto a ontologia, apenas

\footnotetext{
${ }^{17}$ Isso sobretudo porque a busca pelo sentido do ser, partindo do ente, não será mais o interesse da filosofia heideggeriana após Sein und Zeit.
}

Morte e finitude na filosofia de Martin Heidegger: uma intuição de sein und zeit ao pensamento da história do ser - José Reinaldo F. Martins Filho 
poderão ser consideradas enquanto empreendimentos da finitude: a filosofia, como sua tarefa; a ontologia, como o seu índice (cf. STEIN, 2001). Este é o caráter positivo da finitude, que, segundo Heidegger, constitui o percurso de toda e qualquer filosofia autêntica.

\section{Referências bibliográficas}

BAY, Tatiana Aguilar-Álvarez. El lenguaje en el primer Heidegger. Prólogo de Ramón Xirau. Ciudad del México: Fondo de Cultura Económica, 1998.

BELO, Fernando. Heidegger pensador da terra. Covilhã, Portugal: Universidade da Beira Interior, LusoSofiaPress, 2011.

CORVEZ, Maurice. La philosophie de Heidegger. Paris: Press Universitaires de France, 1966.

CUNHA, Helena Parente. "Introdução à leitura hermenêutica em Heidegger". In. Revista Tempo brasileiro, jul/set, n. 50. Rio de Janeiro, 1977.

DASTUR, Françoise. Heidegger e a questão do tempo. Lisboa: Instituto Piaget, 1990. (Coleção Pensamento e Filosofia)

DESCARTES, René. Discurso do Método. Tradução de Enrico Corvisieri. São Paulo: Editora Nova Cultural Ltda., 2000a. (Coleção Os Pensadores)

DESCARTES, René. Meditações. Tradução de Enrico Corvisieri. São Paulo: Editora Nova Cultural Ltda., 2000b. (Coleção Os Pensadores)

DESCARTES, René. Meditações sobre filosofia primeira. Edição Bilíngue Latim/Português. Tradução de Fausto Castilho. Campinas: Edições CEMODECON, 1999.

DUARTE, André. "Heidegger e o outro: a questão da alteridade em Ser $e$ Tempo". In. Natureza Humana, vol. 4, n. 1, jan/jun. Curitiba: Editora UFPR, 2002a. pp. 157-185.

DUARTE, André. "Foucault à luz de Heidegger: notas sobre o sujeito autônomo e o sujeito constituído". In. Imagens de Foucault e Deleuze, ressonâncias nietzschianas. Organizado por Margareth Rago, Luiz B. Lacerda Orlandi, Alfredo Veiga-Neto. Rio de Janeiro: DP\&A, 2002b. pp. 49-62.

DUBOIS, Christian. Introdução ao pensamento de Heidegger. São Paulo: Jorge Zahar Editor, 2005.

FERREIRA, Acylene Maria Cabral. "A finitude do tempo em Heidegger". In. SALLES, João Carlos (org.). Filosofia e consciência social. Salvador: Quarteto, 2003. pp. 9-18.

FRAGA, Gustavo de. De Husserl a Heidegger: elementos para uma problemática da fenomenologia. Coimbra: Universidade de Coimbra, 1966. (Instituto de Estudos Filosóficos)

GIACOIA JÚNIOR, Oswaldo. Heidegger urgente: introdução a um novo pensar. São Paulo: Três Estrelas, 2013.

Morte e finitude na filosofia de Martin Heidegger: uma intuição de sein und zeit ao pensamento da história do ser - José Reinaldo F. Martins Filho 
GONZÁLBEZ, Maria Fernanda Benedito. Heidegger em su lenguaje. Madrid: Editorial Tecnos, 1992. (Colección Metropolis)

HAAR, Michel. Heidegger e a essência do homem. Lisboa: Instituto Piaget, 1990. (Coleção Pensamento e Filosofia)

HEIDEGGER, Martin. Aus der Erfahurng des Denkens. Frankfurt am Main: Vittorio Klostermann, 1983. Gesamtausgabe: Band XIII. Abteilung: Veröffentlichte schriften 1910-1976. Tradução brasileira de Maria do Carmo Tavares de Miranda: Da experiência do pensar. Porto Alegre: Editora Globo, 1969.

HEIDEGGER, Martin. "Brief über den humanismus". In. Wegmarken. Frankfurt am Main: Vittorio Klostermann, 1976. Gesamtausgabe: Band IX. Abteilung: Veröffentlichte schriften 1914-1970. Tradução brasileira de Rubens Eduardo Farias: Carta sobre o humanismo. São Paulo: Centauro, 2005.

HEIDEGGER, Martin. "Die Zeit des Weltbildes". In. Holzwege. Frankfurt am Main: Vittorio Klostermann, 1977. Gesamtausgabe: Band VI. Abteilung: Veröffentlichte schriften 1914-1970. Tradução brasileira de Cláudia Drucker: A época das imagens de mundo, com consulta às traduções de Wolfgang Brockmeier para o francês, em Chemins que ne mènent nulle part (Gallimard, 1986, pp. 99-146), e de William Lovitt para o inglês, em The question concerning technology and other essays (Nova Iorque: Harper, 1977, pp. 115-154).

HEIDEGGER, Martin. Identität und Differenz. Frankfurt am Main: Vittorio Klostermann, 2006. Gesamtausgabe: Band XI. Abteilung: Veröffentlichte schriften 1910-1976. Tradução brasileira de Ernildo Stein: "Identidade e Diferença". In. Conferências e escritos filosóficos. 4.ed. São Paulo: Nova Cultural, 1991. pp. 137-162. (Coleção Os Pensadores)

HEIDEGGER, Martin. "Kants these über das Sein". In. Wegmarken. Frankfurt am Main: Vittorio Klostermann, 1976. Gesamtausgabe: Band IX. Abteilung: Veröffentlichte schriften 1914-1970. Tradução brasileira e notas de Ernildo Stein: "A tese de Kant sobre o Ser". In. Conferências e escritos filosóficos. São Paulo: Nova Cultural, 1989. pp. 179-202. (Coleção Os Pensadores)

HEIDEGGER, Martin. Kant und das problem der metaphysik. Frankfurt am Main: Vittorio Klostermann, 1991. Gesamtausgabe: Band III. Abteilung: Veröffentlichte schriften 1910-1976. A tradução dos fragmentos citados no texto é nossa.

HEIDEGGER, Martin. "La Fin de la Philosophie et la Tâche da la Pensée". In. Kierkegaard Vivant. Colloque organisé par l'Unesco à Paris du 21 au 23 avril 1964. Traductionpar Jean Beaufret et François Fédier. Paris: Gallimard, 1966. pp. 165ss. Tradução brasileira de Ernildo Stein: "O Fim da Filosofia e a Tarefa do Pensamento". In. Conferências e escritos filosóficos. 4.ed. São Paulo: Nova Cultural, 1991. pp. 65-82. (Coleção Os Pensadores)

Morte e finitude na filosofia de Martin Heidegger: uma intuição de sein und zeit ao pensamento da história do ser - José Reinaldo F. Martins Filho 
HEIDEGGER, Martin. "Mein Weg in die Phänomenologie". In. Zu Sache des Denkens. Frankfurt am Main: Vittorio Klostermann, 2007. Gesamtausgabe: Band XIV. Abteilung: Veröffentlichte schriften 19101976. Tradução portuguesa de Ana Falcato: $O$ meu caminho na fenomenologia. Covilhã, Portugal: Universidade da Beira Interior, LusoSofiaPress, 2009. (Textos Clássicos de Filosofia)

HEIDEGGER, Martin. Nietzsche: Metaphysik und Niilismus. Frankfurt am Main: Vittorio Klostermann, 2006. Gesamtausgabe: Band LXVII. Abteilung: Veröffentlichte schriften 1910-1976. Tradução brasileira de Marco Antônio Casanova: Nietzsche: Metafísica e Niilismo. Rio de Janeiro: Relume Dumará, 2000. (Conexões)

HEIDEGGER, Martin. Nietzsche II. Frankfurt am Main: Vittorio Klostermann, 1961. Gesamtausgabe: Band VI-I. Abteilung: Veröffentlichte schriften 1910-1976. Tradução brasileira de Marco Antônio Casanova: Nietzsche. Vol. II. Rio de Janeiro: Forense Universitária, 2007.

HEIDEGGER, Martin. Sein und Zeit. Frankfurt am Main: Vittorio Klostermann, 1977. Gesamtausgabe: Band II. Abteilung: Veröffentlichte schriften 1914-1970. Tradução brasileira, organização, nota prévia, anexos e notas de Fausto Castilho: Ser e Tempo. Campinas, SP: Editora Unicamp; Petrópolis, RJ: Editora Vozes, 2012.

HEIDEGGER, Martin. "Vom Wesen des Grundes." In. Wegmarken. Frankfurt am Main: Vittorio Klostermann, 1976. Gesamtausgabe: Band IX. Abteilung: Veröffentlichte schriften 1914-1970. Tradução brasileira de Ernildo Stein: "Sobre a Essência do Fundamento". In. Conferências $e$ escritos filosóficos. São Paulo: Nova Cultural, 1989. pp. 83-116. (Coleção Os Pensadores)

HEIDEGGER, Martin. "Was ist das - die Philosophie?". In. Wegmarken. Frankfurt am Main: Vittorio Klostermann, 1976. Gesamtausgabe: Band IX. Abteilung: Veröffentlichte schriften 1914-1970. Tradução brasileira de Ernildo Stein: "O que é isto - a filosofia?". In. Conferências e escritos filosóficos. 4.ed. São Paulo: Nova Cultural, 1991. pp. 07-24. (Coleção Os Pensadores)

HEIDEGGER, Martin. "Was ist Metaphysik?”. In. Wegmarken. Frankfurt am Main: Vittorio Klostermann, 1976. Gesamtausgabe: Band IX. Abteilung: Veröffentlichte schriften 1914-1970. Tradução brasileira de Ernildo Stein: "Que é Metafísica?”. In. Conferências e escritos filosóficos. São Paulo: Nova Cultural, 1989. pp. 25-64. (Coleção Os Pensadores)

HEIDEGGER, Martin. Zollikoner Seminare. Protokolle - Gespräche Brief. Hrsg. von Medard Boss. Frankfurt am Main: Vittorio Klostermann, 1987. Gesamtausgabe: Band LXXXIX. Tradução brasileira de Gabriella Arnhold e Maria de Fátima de Prado: Seminários de Zóllikon. Petrópolis, RJ: Vozes, 2001. 
INWOOD, Michael. Dicionário Heidegger. Tradução de Luísa Buarque de Holanda; revisão técnica de Márcia Sá Cavalcante Schuback. Rio de Janeiro: Jorge Zahar Editor, 2002. (Dicionários de Filósofos)

KOTHE, Flávio R. "Caminhos e descaminhos da Crítica: Encontro com Heidegger”. In. Revista Tempo brasileiro, jul/set, n. 50. Rio de Janeiro, 1977. pp. 49-59.

LEÃO, Emmanuel Carneiro. "Heidegger e a Modernidade: a correlação de sujeito e objeto". In. Revista Tempo brasileiro, jul/set, n. 50. Rio de Janeiro, 1977. pp. 03-26.

LOPARIC, Zeljko. Heidegger. Rio de Janeiro: Jorge Zahar Editor, 2004. (Passo-a-passo, 32)

MACDOWELL, João Augusto A. Amazonas. A gênese da ontologia fundamental de Martin Heidegger: ensaio de caracterização do modo de pensar de Sein und Zeit. São Paulo: Loyola, 1993. (Coleção Filosofia)

MARQUES, Jordino. "O Ser-com Heideggeriano". In. Fragmentos de Cultura, v. 8, n. 1, jan/fev. 1998. pp. 19-32.

MARQUES, Jordino. "Linhas gerais do método fenomenológico husserliano”. In. Philósophos. Goiás, v. 2, n. 2, jul/dez, 1997. pp. 45-54.

MARQUES, Jordino. "O método fenomenológico em Husserl e Heidegger: diferenças e aproximações”. In. Philósophos. Goiás, v. 2, n. 1, jan/jun, 1997. pp. 11-28.

MONDADORI, Oscar. Karl Jaspers: notas sobre Heidegger. Introducción de Hans Saner. Madrid: Mondadori España, 1990.

MÜLLER-GRANZOTTO, Marcos José. "Resenha: Compreensão e finitude - estrutura e movimento da interrogação heideggeriana”. In. Natureza Humana, v. 7, n. 1, jan/jun, 2005. pp. 253-263.

NUNES, Benedito. Heidegger \& Ser e Tempo. 2.ed. Rio de Janeiro: Jorge Zahar Editor, 2004. (Passo-a-passo, 6)

PASQUA, Hervé. Introdução à leitura do Ser e Tempo de Martin Heidegger. Tradução de Joana Chaves. Lisboa, Portugal: Instituto Piaget, 1993. (Pensamento e Filosofia)

PISETTA, Écio Elvis. "Morte e finitude". In. Síntese - Revista de Filosofia, v. 34, n. 109. Belo Horizonte, 2007. pp. 219-246.

SA, Alexandre Franco de. Finitude e Liberdade na confrontação de Heidegger com Kant. Covilhã, Portugal: Universidade da Beira Interior, 2009. (Artigos LusoSofia)

SAFRANSKI, Rüdiger. Heidegger: um mestre da Alemanha entre o bem e o mal. Tradução de Lya Lett Luft e apresentação de Ernildo Stein. São Paulo: Geração Editorial, 2005.

SCHUBACK, Márcia Sá Cavalcante. "A perplexidade da presença”. In. HEIDEGGER, Martin. Ser e Tempo. Tradução de Márcia Sá Cavalcante Schuback. 5.ed. Petrópolis, RJ: Vozes; Bragança Paulista, SP: Editora Universitária São Francisco, 2011. (Pensamento Humano)

Morte e finitude na filosofia de Martin Heidegger: uma intuição de sein und zeit ao pensamento da história do ser - José Reinaldo F. Martins Filho 
SCHÜRCH, Franz-Emmanuel. "Heidegger et la Finitude". In. Klesis Revue Philosophique: später Heidegger, n. 15, 2010. pp. 6-27.

SLOTERDIJK, Peter. Regras para o parque humano: uma resposta à carta de Heidegger sobre o humanismo. Tradução de José Oscar de Almeida Marques. São Paulo: Estação Liberdade, 2000.

STEIN, Ernildo. Compreensão e finitude: estrutura e movimento da interrogação heideggeriana. Ijuí: Ed. Unijuí, 2001. (Coleção ensaios política e filosofia)

TERNES, José. "Analítica da finitude: Kant, Heidegger, Foucault". In. Philósophos. Goiás, v. 3, n. 2, jul/dez, 1998. pp. 47-59.

VALENTIM, Marcos Antônio. "Heidegger sobre a fenomenologia husserliana: a filosofia transcendental como ontologia". In. O que nos faz pensar, n. 25, agosto de 2009. pp. 213-238.

WERLE, Marco Aurélio. Poesia e pensamento em Hölderlin e Heidegger. São Paulo: Editora Unesp, 2005.

ZANETTE, Edgard Vinícius Cacho. "Notas sobre a interpretação heideggeriana da subjetividade e do cogito cartesiano". In. Griot - Revista de Filosofia, v. 6, n. 2, Amargosa, Bahia, dezembro, 2012. pp. 27-40.

ZARADER, Marlene. Heidegger et les paroles de l'origine. Preface de Emmanuel Lévinas. Paris: Limbrairie Philosophique J. Vrin, 1986. 